A R T I G O

\title{
HUMANIDADES DIGITAIS E LEITURA NO TWITTER: "UM PLACEBO SANADOR EM TEMPOS DE COVID-19"
}

Digital humanities and reading on Twitter. "A placebo that heals in times of COVID-19"

Humanidades digitales e leitura no Twitter. "Un placebo sanador en tiempos de COVID-19"

ALEJANDRA JUDITH JOSIOWICZ ${ }^{1^{*}}$

DOl: https://doi.org/10.1590/S2178-149420210207

'Departamento de Letras Neolatinas, Instituto de Letras, Universidade do Estado do Rio de Janeiro - Rio de Janeiro (RJ), Brasil. *Professora Adjunta, Departamento de Letras Neolatinas, Instituto de Letras, Universidade do Estado do Rio de Janeiro. Pósdoutora pelo Centro de Pesquisa e Documentação de História Contemporânea do Brasil (alejandra.josiowicz@gmail.com).

(D) https://orcid.org/0000-0002-3525-1833

Artigo recebido em 21 de outubro de 2020 e aprovado para publicação em 24 de março de 2021. 


\title{
RESUMo
}

0 presente artigo parte de uma crítica cultural computacional para analisar as práticas de leitura ao longo da pandemia pela COVID-19 por meio do uso do Twitter. Analisam-se tweets com referências a dois autores, Clarice Lispector e Jorge Luis Borges, os quais foram extraídos e analisados utilizando softwares de mineração de texto. Esses autores foram mobilizados em dois sentidos principais: em um sentido terapêutico, modo de lidar com a solidão e o sofrimento, e para processar as transformações sociais e coletivas, expressando apoio ou oposição às políticas dos governos ante a COVID-19. 0 trabalho conclui que as práticas de leitura desses autores colocaram em cena os modos múltiplos de viver a pandemia e deram forma à experiência subjetiva e coletiva.

PALAVRAS-CHAVE: Humanidades Digitais; Práticas de Leitura; Sul Global; Clarice Lispector; Jorge Luis Borges; Mídias Sociais.

\begin{abstract}
This article follows a computational cultural criticism to analyse the reading practices on Twitter during the COVID-19 pandemic. It analyses tweets that reference Jorge Luis Borges and Clarice Lispector, which were extracted and analysed using textual mining tools. The article demonstrates that both authors were mobilized in two different senses: in a therapeutic sense, as a way to deal with loneliness and suffering, and also to process collective and social transformations, expressing support or criticism of governmental politics dealing with COVID-19. In those ways, the article shows that reading practices on Twitter reveal the multiples ways in which people experienced the pandemic, and shaped collective and subjective experience.
\end{abstract}

KEYWORDS: Digital Humanities; Reading Practices; Global South; Clarice Lispector; Jorge Luis Borges; Social Media.

\section{RESUMEN}

El presente artículo parte de una crítica cultural computacional para analizar las prácticas de lectura durante la pandemia de COVID-19 a través del uso de Twitter. Se analizan tweets con referencia a dos autores, Clarice Lispector e Jorge Luis Borges, los cuales fueron extraídos y analizados utilizando softwares de mineración textual. El artículo demuestra que los autores fueron movilizados en dos sentidos diferentes: en un sentido terapéutico, modo de lidiar con la soledad y el sufrimiento, y también para procesar las transformaciones sociales y colectivas, expresando apoyo u oposición a las políticas de los gobiernos ante el COVID-19. El trabajo concluye que las prácticas de estos autores pusieron en escena los modos múltiples de vivir la pandemia de COVID-19 y dieron forma a la experiencia subjetiva y colectiva.

PALABRAS CLAVE: Humanidades Digitales; Prácticas de Lectura; Sur Global; Clarice Lispector; Jorge Luis Borges; Redes Sociales. 
presente artigo analisa as práticas de leitura ao longo da pandemia pela COVID-19 por meio do uso do Twitter para citar, circular, compartilhar e referenciar autores e textos literários. Analisam-se tweets com referências a dois autores centrais para o cânone da literatura latino-americana, Clarice Lispector e Jorge Luis Borges, os quais foram extraídos e analisados utilizando softwares de mineração de texto. Com a expansão da leitura digital, e ainda mais com a atual emergência de saúde, com as medidas de distanciamento e o isolamento social decorrentes da COVID-19, Borges e Lispector, autores que circularam amplamente no mercado de consumo latino-americano desde a segunda metade do século XX, tornaram-se objetos de práticas de leitura digital, circulação e recepção, lidos, citados e rescritos nas redes sociais, especificamente no Twitter. 0 artigo demonstra que o Twitter foi mobilizado ao longo da pandemia como espaço de leitura desses dois autores em dois sentidos principais: por um lado, em um sentido terapêutico, modo de lidar com a solidão, o sofrimento e a angústia que caracterizaram o momento. Por outro, para lidar com as transformações sociais e coletivas decorrentes da pandemia, expressando apoio ou oposição às políticas dos governos ante a COVID-19, alertando sobre o uso de máscaras ou expressando críticas aos governos. Por meio desses dois eixos, o artigo revela que as práticas de leitura de Borges e Lispector no Twitter proveram um vocabulário compartilhado para falar sobre temas importantes no contexto da pandemia de COVID-19, como a saúde física e psíquica, a morte e a solidão. Além disso, sua leitura canalizou posicionamentos políticos e mobilizações coletivas em direções ideológicas às vezes opostas. As práticas de leitura de Borges e Lispector colocaram em cena os modos múltiplos de viver a pandemia pela COVID-19 e deram forma às experiências subjetiva e coletiva, como instrumentos de autoconhecimento, mas também de diálogo com a sociedade.

0 artigo está dividido em três partes. Na primeira parte, apresenta o marco teórico geral da sociologia da leitura, das humanidades digitais e da análise crítica tecnocultural do discurso. Além disso, identificam-se teoricamente as duas modalidades da leitura que são analisadas em tempos de pandemia. Primeiramente, abordam-se estudos que colocam o foco na leitura e seu efeito terapêutico no nível da subjetividade. Em segundo lugar, recuperam-se autores que focalizam os sentidos sociais, cívicos e políticos da leitura. Sobretudo na segunda modalidade, fazem-se considerações que dizem respeito à perspectiva geopolítica e às desigualdades das formas de leitura no Norte e no Sul global. Na segunda parte, identificam-se os dados das extrações de tweets em diferentes línguas: os idiomas mais comuns, as características formais e estilísticas dos tweets, os termos mais frequentes e os temas principais. Na terceira parte, expõem-se as conclusões à luz das teorias supracitadas, com foco nas duas 
modalidades fundamentais da leitura, fazendo considerações sobre como o contexto e as características específicas da pandemia de COVID-19 impactaram essas práticas. Desse modo, 0 artigo demonstra a enorme vitalidade da leitura em tempos de pandemia, como defesa ante 0 desânimo e canal de ativismo político, capaz de mobilizar os sujeitos e as opiniões.

\section{SOCIOLOGIA DA LEITURA E LEITURA DISTANTE EM TEMPOS DE PANDEMIA}

$\mathrm{O}$ contexto da pandemia de COVID-19 pode ser caracterizado como um "momento de absoluta tensão, manifesta como uma enervação do corpo coletivo, uma histeria generalizada, vista através das redes sociais" (Casa Nova Maia e Casa Nova, 2020: 2). A pandemia aprofundou as desigualdades sociais, econômicas, raciais, sexuais e ampliou as desigualdades entre as nações do Sul e do Norte global (Butler, 2020). Apressou a passagem para uma sociedade ciberoral, digital, acrescentou a importância das tecnologias informáticas móbiles, a inteligência artificial e de algoritmos de uso de Big Data, o intercâmbio de informação a grandes velocidades, como parte da gestão semiótico-técnica digital (Preciado, 2020: 172). Em tempos de pandemia, o político e o biopolítico inscreveram-se no corpo individual (Preciado, 2020; 184)․ A revolução digital da leitura vinha modificando, em décadas recentes, a materialidade, os suportes e as técnicas de reprodução e disseminação dos textos (Chartier, 2017). 0 entorno digital e o texto eletrônico possibilitaram maior protagonismo ao leitor, capaz de transmitir suas opiniões em foros públicos e redes sociais, o que conferiu um caráter coletivo, espontâneo e fragmentário à leitura (Chartier, 2017). A prática leitora vinha se tornando mais dispersa, errante e ativa, e ligada a imagens, vídeos, hyperlinks. Os textos digitais começavam a ser acessados frequentemente em sítios online, alguns legítimos, outros clandestinos, o que vinha ampliando o público leitor para além daqueles que podem custear a compra de livros e frequentar livrarias e bibliotecas. 0 contexto da pandemia de COVID-19 reforçou esse processo, aprofundando a importância dos discursos tecnoculturais e o papel das redes sociais no cotidiano das pessoas.

0 Twitter tem funcionado como um foro literário público, um termómetro da leitura, no qual os usuários seguem contas de autores, editoras e revistas literárias, comentam suas leituras, leem, recomendam, expressam gosto ou desgosto e mobilizam textos e autores para os mais variados fins ${ }^{2}$. Por meio do Twitter, a leitura quotidiana e digital em tempos de pandemia é inscrita e formalizada na economia mais extensa do consumo cultural online (Van Dijck, 2013). A microssintaxe enxuta do tweet - inicialmente restrito a 140 caracteres e depois a 240 — tem permitido ampliar o público dos leitores para além daqueles que têm o hábito de 
circular por livrarias, bibliotecas ou realizar atividades educacionais de leitura, chegando a leitores que leem em fragmentos e citações, compartilham frases e fotografias dos autores como parte de sua vida quotidiana, escrevem suas reações, formando uma comunidade de leitura e escrita no Twitter. Como infraestrutura de comunicação online e interação social, o Twitter está longe de ser um âmbito neutro de interação, engajamento, intercâmbio de opiniões e comunicação pública de conteúdo (Brock, 2012). Ferramentas de filtragem, algoritmos e técnicas como hashtags, trending topics e retweets delineiam uma estrutura hierárquica na qual poucos usuários hiper-conectados ganham influência para manipular opiniões e condicionar ideias (Van Dijck, 2013).

Como a análise crítica do discurso tecnocultural tem demonstrado, as tecnoculturas digitais remetem a um campo dominado por ideologias tecnocráticas, corporativas, que privilegiam o masculino em detrimento do feminino, o anglo-saxão em detrimento de outras línguas e o Norte em detrimento do Sul (Brock, 2012, 2020; Risam, 2018). Para as comunidades digitais do Sul global e especificamente latino-americanas, as tecnologias tendem a reproduzir estereótipos de atraso, passividade, falta de conhecimento tecnológico, apontando para desigualdades e hierarquias globais e linguísticas e olhares etnocêntricos (Brock, 2012, 2020; Silva, 2020). No entanto, o que pode parecer simples entretenimento do ponto de vista do Norte global — como é a discussão e o compartilhamento de autores e citações literárias no Twitter — resulta para as comunidades de leitores do Sul uma forma de drama ritual ou catarse no qual expressar opiniões políticas, visões de sociedade, comunicar sentidos vitais e subjetivos ante dificuldades e crises econômicas, instabilidade política, problemas de saúde física e mental.

Desde a perspectiva da teoria materialista e de um "programa forte" de sociologia cultural, as práticas de leitura digital devem ser pensadas como produtoras de sentidos sociais que não preexistem à recepção dos públicos (Williams, 1977; Alexander, 2011). Em lugar de se restringir à leitura canônica de textos e autores, as comunidades digitais mobilizam-nos para discutir crises pessoais e sociais, desigualdades raciais, de gênero e opiniões políticas. Trata-se de operações significantes que são a evidência material e a consciência prática de um processo social e contribuem com esse processo de forma dinâmica, contínua e em mudança (Williams, 1977; Alexander, 2011). Em um momento de profundas transformações históricas, instabilidade e crise, os sujeitos fazem uso de ferramentas de leitura e escrita digital e mobilizam sentidos, propõem ações sociais, buscam aliados, inovam e lutam recriando a herança cultural compartilhada sinalizada por Borges e Lispector. Eles utilizam meios de produção simbólica digital e plataformas de redes sociais para comunicar aos outros suas preocupações, emoções e sofrimentos, mobilizando questões sociais, culturais e políticas (Alexander, 2011). 
A leitura aparece como modo de agência ao interior de uma pragmática cultural, forma de construir sentidos, de agir, tanto no nível subjetivo e sentimental como no plano político: por meio da leitura, os sujeitos repensam a própria constituição da comunidade e a esfera civil (Alexander, 2011).

As humanidades digitais e especificamente a chamada "leitura distante" propõem observar grandes sistemas de produções culturais partindo de uma crítica cultural computacional e um grande volume de dados empíricos e utiliza padrões abstratos para analisar o significado cultural (Moretti, 2017; Lee e Martin, 2015). Desse modo, incorpora métodos computacionais experimentais e uma perspectiva macroscópica aos estudos culturais (Underwood, 2017)3. A "leitura distante" enfatiza o protagonismo dos públicos leitores na formação e transformação dos cânones, dado que recriam e circulam os textos, valorizam um ou outro aspecto deles e conferem-Ihes novos significados, ligados à sua própria experiência de leitura (Underwood, 2017; Moretti, 2017)4. No entanto, o campo das humanidades digitais tem privilegiado a abordagem metodológica dos métodos computacionais, por sobre questões de gênero, raça e geopolítica (Callaway et al., 2020). Propomos uma perspectiva pós-colonial que considere desigualdades geopolíticas, linguísticas e culturais entre o Norte e o Sul global, entre o mundo anglo-saxão, o lusófono e o hispanófono (Risam, 2018), entre os públicos leitores e os sentidos que mobilizam.

A escolha de Clarice Lispector e Jorge Luis Borges, autores canônicos com alta circulação no mundo inteiro, justifica-se pela proximidade de ambos com as demandas dos mercados culturais e a produção destinada aos públicos massivos, assim como pela circulação no mercado literário mundial, as quais não são fenômenos recentes. Os dois participaram da expansão do mercado de publicações impressas na América Latina, que circulou de forma global já entre as décadas de 1960 e 1970, o que contribuiu para aumentar suas vendas e expandir seu público leitor ao longo da segunda metade do século XX (Siskind, 2014; Rama, 1981). Borges e Lispector escreveram romances, crônicas e livros de contos, alguns deles inicialmente aparecidos em jornais, revistas e magazines, de circulação considerável no mercado literário e na imprensa já no momento de sua publicação, o que ressalta sua estreita relação com amplos públicos leitores (Saítta, 2018; Arêas, 2005; Méndez, 2019; Josiowicz, 2019). Seus livros foram traduzidos desde as décadas de 1950 e 1960 e circularam amplamente no mercado global, como parte do boom da literatura latino-americana (Rama, 1981)5. Esse processo de massificação da literatura de Borges e Lispector se tornou mais intenso em décadas recentes, com a expansão da leitura digital e a divulgação dos autores em foros públicos como o Twitter, que funciona como estímulo e espaço de articulação das práticas de leitura. Dadas as medidas de isolamento e distanciamento social ao longo da pandemia de COVID-19, muitos leitores 
preferiram comprar ou acessar livros exclusivamente em formato digital e aumentaram o uso e a presença em foros públicos.

A seleção surgiu de um mapeamento de distintos autores argentinos e brasileiros e da avaliação do caráter socialmente significativo das menções a eles e seus textos nas redes sociais. Após uma série de tentativas com diferentes autores, Borges e Lispector, embora com trajetórias intelectuais e bagagens culturais diferentes, foram elencados como os mais relevantes em termos qualitativos e quantitativos, dada sua presença entre os públicos do Twitter ${ }^{6}$.

As práticas da leitura no Twitter com base em Borges e Lispector ao longo da pandemia pela COVID-19 apontam para dois tipos de sentidos principais. Por um lado, os usuários do Twitter mobilizam Borges e Lispector no sentido da compreensão de si, do autoconhecimento, de lidar com as próprias emoções e experiências subjetivas. Pesquisas da sociologia da leitura vêm demonstrando que a experiência corporal, emocional, de ler e citar autores e textos literários é capaz de oferecer aos sujeitos um espaço para processar suas experiências e emoções mais íntimas, as transformações do eu, lidar com stress e desenvolver estratégias de resiliência, o que se torna ainda mais relevante em casos de confinamento (Olave, 2018). A leitura adquire um caráter terapêutico, de autoajuda, como um termômetro das emoções subjetivas, que não só transmitem sensações previamente existentes, mas mobilizam, estimulam, canalizam novas, constroem intimidade (Illouz, 2008). Esse tipo de uso não é uma novidade: na Argentina, desde as primeiras décadas do século XX, a literatura de folhetim, na qual o "sentimental", as emoções e os afetos, cumpriu papel central, contribuiu para treinar um público alheio às elites culturais e literárias, de setores médios e populares, sobretudo muIheres e jovens, nas práticas de leitura (Sarlo, 2011). Esteve presente em Clarice Lispector, que foi uma leitora de textos terapêuticos, psicológicos e manuais de autoajuda e que incorporou essa literatura psicanalítica e de autoajuda nas suas crônicas nos jornais e colunas em revistas (Josiowicz, 2020).

Por outro lado, os usuários não anglo-saxões do Twitter citam, leem e escrevem sobre Borges e Lispector mobilizando sentidos sociais e políticos. Os estudos culturais e a sociologia cultural assinalam que a produção simbólica não só está marcada pela relação entre a consciência individual e a produção de sentidos sociais (Williams, 1977), mas, sobretudo, é uma variável independente na formação da vida social, com efeito nas instituições, na política e na cultura (Alexander, 2011). Por seu lado, a análise crítica tecnocultural do discurso demonstrou que as tecnologias de comunicação e informação estão ligadas às ideologias, às crenças e aos sentidos culturais produzidos e reproduzidos nas práticas dos usuários (Brock, 2020). Os usuários apropriam-se do artefato tecnológico - no caso, a leitura digital no Twitter - e dão-Ihe forma de acordo com o espaço tecnocultural no qual operam e existem, por 
meio de práticas discursivas pelas quais constroem significados (Brock, 2020). Desse modo, os sentidos políticos que os usuários do Sul global, não anglo-saxões, dão às suas práticas de leitura não devem ser desprezados como usos incorretos ou deficientes, mas devem ser entendidos como estreitamente ligados com os contextos institucionais e culturais nos quais experimentaram a pandemia de COVID-19. Esse caráter político dos sentidos literários não é um fenômeno recente e remete a uma herança cultural compartilhada na América Latina (Sarlo e Altamirano, 2001).

\section{UM MAPA DA LEITURA DE BORGES E LISPECTOR EM TEMPOS DE PANDEMIA}

\section{A LEITURA DE LISPECTOR E BORGES NO TWITTER: UMA ANÁLISE FORMAL QUANTITATIVA}

$\mathbf{E}^{\mathrm{s}}$ sta pesquisa parte de uma série de extrações do Twitter pelo software Wolfram Mathematica feitas entre maio e setembro de 2020, período em que a pandemia de COVID-19 afetou de modo intenso o mundo inteiro. Foram feitas extrações diárias de tweets que mencionassem a frase Jorge Luis Borges ou Clarice Lispector, coletando até 5.000 tweets cada vez, utilizando a função de busca e extração existente no software Wolfram Mathematica, na versão 12.1. Wolfram Mathematica é um sistema computacional que utiliza uma linguagem de programação de alto nível construída em torno de um motor computacional poderoso, de aprendizado relativamente simples. Desse modo, oferece uma possibilidade inovadora de aplicar o pensamento computacional à pesquisa nas humanidades, útil para analisar as transformações da leitura e do consumo literário em tempos de pandemia.

Seguindo determinações éticas de melhores práticas sugeridas em estudos das redes sociais e especificamente do Twitter (Bergis et al., 2018), a pesquisa protegeu a privacidade dos usuários, não revelou nomes ou pseudônimos e sempre solicitou autorização aos sujeitos para citar tweets. Buscaram-se pelas referências a Clarice Lispector e Jorge Luis Borges nessa plataforma, com um total de 158.702 tweets sobre Borges e 86.582 sobre Lispector ${ }^{7}$. Se considerarmos os tweets sem retweets, temos um total de 30.997 para Borges e 31.975 para Lispector. A distinção entre tweets originais e retweets permite verificar as dimensões da circulação e da produção no Twitter, equiparáveis com escrita e leitura respectivamente. Desse modo, podemos afirmar que os leitores de Lispector escrevem relativamente mais, produzem mais conteúdo, enquanto os leitores de Borges tendem a ler, reproduzindo e repostando o que outros usuários produzem. 
Seguindo técnicas de estilística quantitativa, os traços formais e padrões textuais medidos em termos quantitativos, como o tamanho e a extensão do texto, podem ser analisados como sintomáticos da estrutura do público leitor, suas práticas de leitura e escrita (Moretti, 2016). Partindo dessa premissa, realizaram-se uma série de estatísticas textuais, com base nas quais foi possível apreciar as características formais do corpus de tweets com e sem retweets, capaz de revelar a dinâmica das práticas de escrita e leitura em nosso corpus. A extensão média dos tweets, contando retweets, sobre Borges e Lispector é a mesma, em torno de 129 caracteres. Sem retweets, temos uma extensão média de 139 para Lispector e 155 para Borges, ou seja, um pouco mais extenso no segundo caso. Importante considerar que o Twitter estendeu o limite de caracteres de 140 a 280 em 2017, mas que, para isso, o usuário precisa ter instalado um plugin. Mesmo com essa mudança, os índices apontam que os tweets costumam ser mais breves: só $12 \%$ ultrapassam o limite de 140 caracteres, sendo a extensão mais comum de 33 caracteres $^{8}$. Nosso corpus se diferencia desses parâmetros porque são tweets longos (ainda mais extensos se desconsiderarmos os retweets), que frequentemente ultrapassam a barreira dos 140 caracteres. Medido em número de palavras, temos uma média de 20 palavras por tweet (com retweets) em Borges e 19 em Lispector. Sem retweets, temos uma média ainda maior, de 24 palavras em Borges e 21 em Lispector.

No histograma da distribuição dos tweets por tamanho em número de caracteres (Figura 1), há grande quantidade de tweets em torno de 140 caracteres tanto em Lispector quanto em Borges, constituindo 35\% em Borges e 32\% em Lispector. Isso se explica não pelo fato de que os usuários

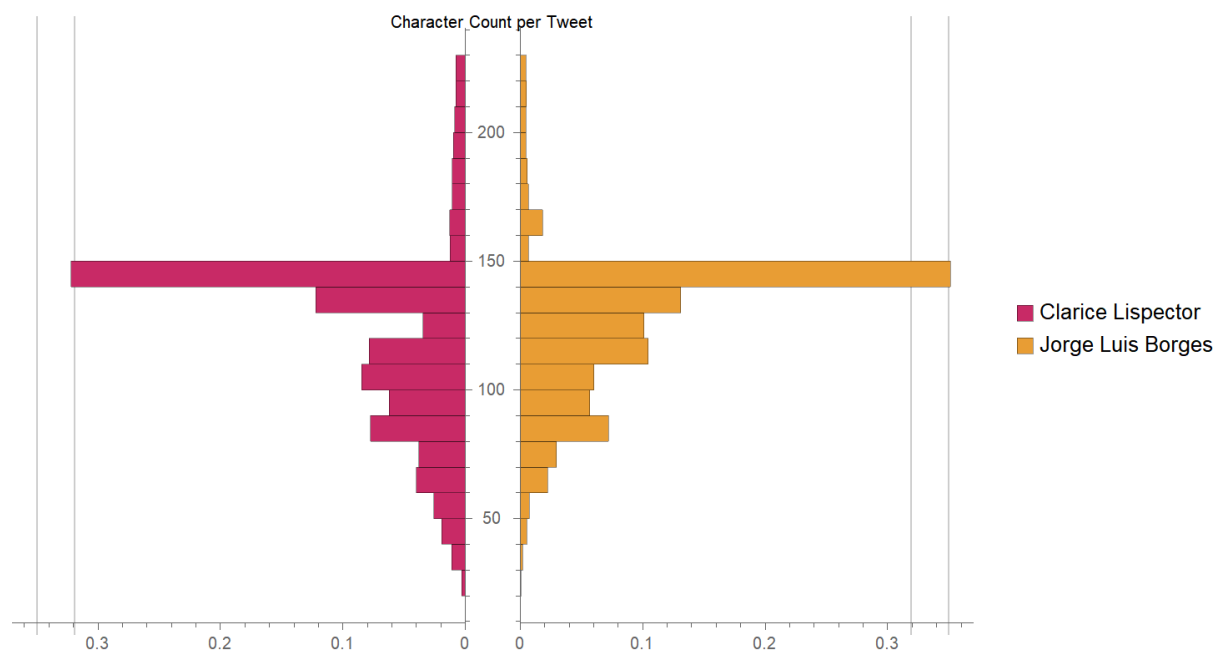

Figura 1 - Histograma dos tweets sobre Lispector e Borges medidos em número de caracteres. 
escrevam exatamente 140 caracteres, mas porque muitos tweets do corpus são maiores que 140, e, quando os usuários que não possuem plugin (que são grande parte) os reencaminham com a ferramenta do retweet, o aplicativo corta o post de acordo com o limite de caracteres, assim ficam exatamente 140 caracteres.

Se considerarmos os tweets sem retweets, os tweets originais, vemos um histograma com uma variedade muito maior na distribuição do tamanho em número de caracteres (Figura 2). Nesse caso, 10\% de tweets sobre Borges são de 160 caracteres e 13\% são de 100 caracteres. No caso de Lispector, as extensões são muito variadas. Em relação a ambos os autores, há abundantes tweets que ultrapassam o limite de 140 e chegam até 240 caracteres. Isso permite afirmar que os leitores de Lispector e Borges, interessados na leitura e na escrita, que citam trechos longos, escrevem muito mais do que os usuários médios do aplicativo.

\section{HASHTAGS}

$\mathrm{E}^{\mathrm{n}}$ ntre as hashtags mais utilizadas nos tweets sobre ambos os autores, são muito comuns as hashtags com os nomes dos autores, além de aquelas relativas ao prazer da escrita, da leitura, a inspiração e a motivação de ler e escrever, a defesa e o estímulo à leitura, assim como hashtags que se referem a instituições ligadas ao estímulo e à difusão da leitura, como bibliotecas, universidades, jornais, revistas e editoras, em diferentes línguas. Há hashtags ligadas à saúde e especificamente ao impacto positivo da leitura na saúde mental e na autoestima, como \#LeerParaCuidarnos, \#SelfCare, \#LoveYourself, \#SaludMental, \#SerySentir-

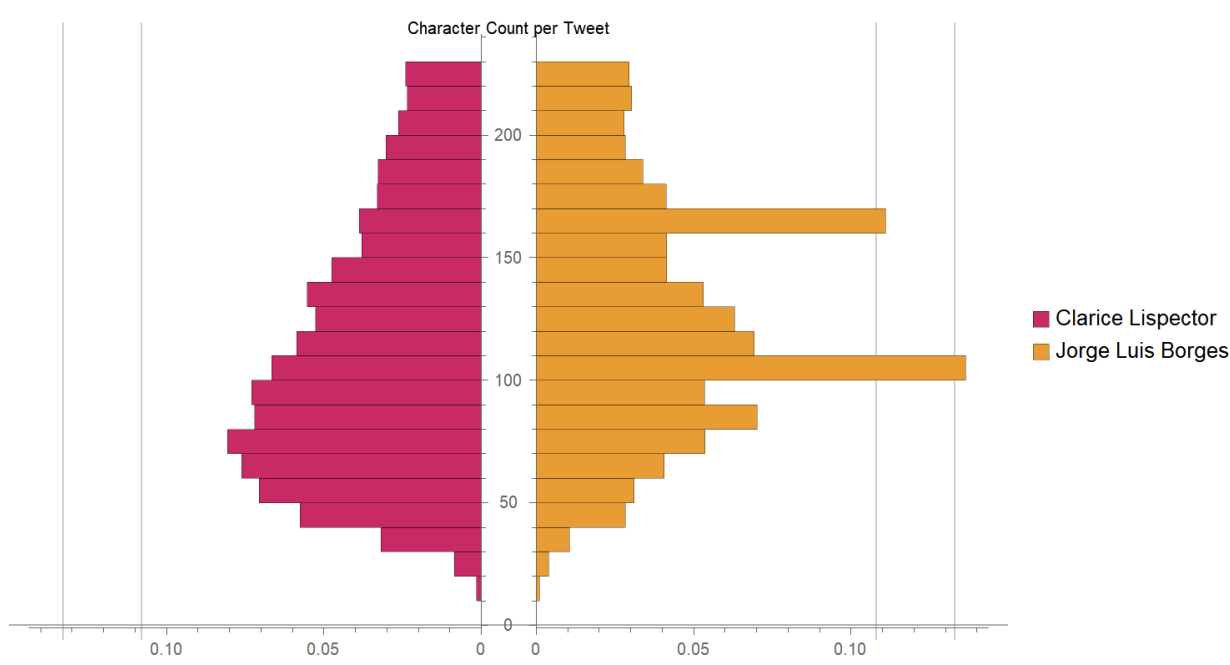

Figura 2 - Histograma dos tweets sem retweets sobre Borges e Lispector em número de caracteres. 
teMejor, \#autoestima, \#LeerNosMueve. Há também aquelas ligadas à leitura como prática noturna, forma de relaxar e facilitar o sono, como \#FateBeiSogni, \#sleep, \#SweetDreams, \#AntesdeDormir. Outro grupo numeroso são aquelas hashtags referindo-se à leitura ao longo da pandemia de COVID-19, que estimulam as pessoas a ficar nos seus domicílios, respeitar o isolamento e aproveitar esse momento para ler: \#QuedateenCasa, \#poesiaparaunaquarentena, \#quarentena, \#Yomequedoencasa, \#YomequedoencasaLeyendo, \#Fiqueemcasa, \#Covid, \#LeiaEmCasa, \#VaiPassar, \#trabajandodesdecasa. Há outras hashtags críticas das medidas de quarentena implementadas em países como a Argentina, como \#cuarentenaeterna. As hashtags sobre Lispector também incluem referências à questão de gênero e à atuação das mulheres na cultura como \#escritoras, \#LiteraturaFeminista, \#EscriturasdeloFemenino, \#ReadMoreWomen e \#WomeninTranslation. Nesse caso, também aparecem posicionamentos políticos como \#ForaBolsonaro.

As hashtags, estratégia central do Twitter e parte integrante de sua estrutura formal, permitem dar mais visibilidade — por meio da estrutura de algoritmos ou trending topics a algumas instituições culturais — editoras, revistas, ministérios de educação, universidades - e políticas de incentivo à leitura. Além disso, apontam para a experiência da leitura em tempos de pandemia, forma de autoconhecimento, reflexão e prazer, e o modo como se tornou estratégia de resiliência e busca de saúde mental, autocuidado, forma de relaxar e de entrar em contato com as próprias emoções. Por meio das hashtags, os leitores expressam sua defesa do livro e da leitura como prática afetiva, emocional, apontando o papel fundamental que o livro tem na vida psíquica e emocional das pessoas ante as medidas de isolamento impostas. A necessidade de ficar em casa, isolados, sem contato com amigos e familiares, e em espaços reduzidos, deu ao livro um papel importante na vida das pessoas. Além disso, a hashtag permite sinalizar posicionamentos sobre determinados temas relevantes para a vida social, como a questão de gênero e o apoio ou crítica aos governos.

\section{NOMES DE USUÁRIOS}

uanto aos usuários mais mencionados e retuitados em ambos os corpora de tweets, é
possível observar alta concentração em alguns usuários: os seis usuários mais retuitados e mencionados em Borges somam 39,6\% de todos os usuários do nosso corpus e $32 \%$ no caso de Lispector. Em ambos os casos, trata-se de contas que se dedicam à publicação de frases e citações literárias (não exclusivamente desses autores), com a finalidade de difusão cultural e com uma relação variável, mais ou menos respeitosa, com a obra dos autores. Em termos de quantidade de menções, temos instituições de língua e leitura, editoras, minis- 
térios de cultura, institutos culturais, revistas, programas de rádio, canais de televisão, jornais, sobretudo localizadas em Argentina, México, Itália, Brasil e Espanha. Também temos algumas personalidades famosas, como apresentadores de televisão, escritores, roteiristas e atrizes localizados em vários países do mundo.

A ferramenta do retweet, que implica citar e reencaminhar o post de outro, a subscrição a uma conta, como seguidor, e a sintaxe do @, que referencia o nome de um usuário, permitem aos leitores ficar conectados uns com outros, intercambiar dicas de leitura, referências e construir uma comunidade de leitura nucleada pelo interesse em Borges ou Lispector. No entanto, não se trata de uma estrutura totalmente horizontal, mas hierárquica, na qual algumas contas com grande quantidade de seguidores são capazes de divulgar e influenciar inúmeras pessoas. 0 Twitter tornou-se parte das políticas de incentivo à leitura, por meio de contas de instituições de divulgação cultural dos setores público e privado, as quais aproveitam a estrutura da plataforma para instrumentar suas estratégias e expandir seus mercados culturais e públicos leitores.

\section{ANÁLISE SEMÂNTICA: NUVENS DE PALAVRAS}

S elecionamos os três idiomas que consideramos mais importantes de nosso corpus — portu$\checkmark$ guês, espanhol e inglês — para o trabalho posterior de análise e processamento. Após uma série de operações de limpeza, construímos nuvens de palavras com as 600 palavras mais comuns no corpus de tweets de cada língua. Nas nuvens de palavras de tweets sobre Lispector (Figura 3), há muitos termos referidos à literatura, à leitura e à escrita, celebrando o centenário do nascimento da autora e mencionando outros autores. Além disso, há muitas palavras referidas a sensações corporais, estados emocionais e afetivos, como solidão, sofrimento, tristeza, melancolia, alegria, assim como à noite como momento preferido para a leitura.
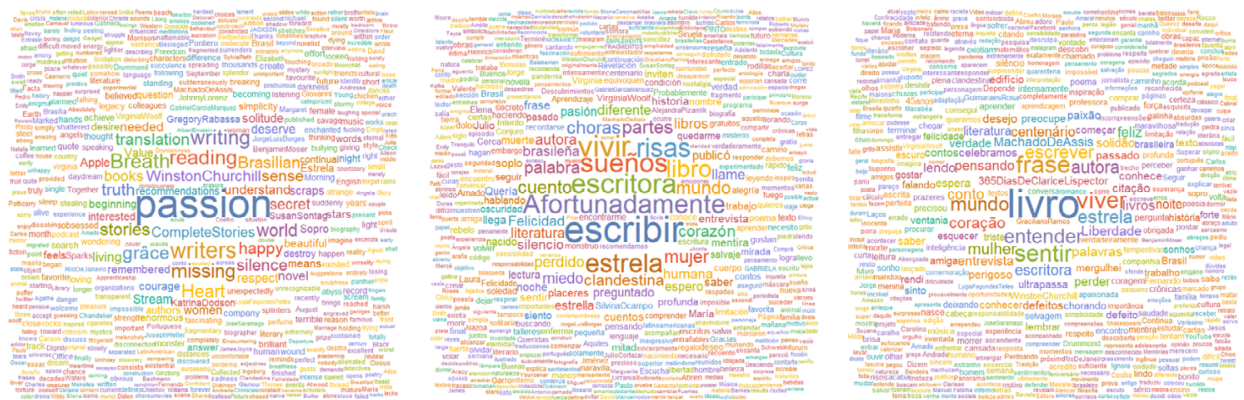

Figura 3 - Nuvens de palavras de tweets sobre Lispector em inglês (esquerda), espanhol (centro) e português (direita). 
Também aparece um número considerável (185) de menções ao presidente do Brasil, Jair Bolsonaro, em tweets de apoio ou crítica. Essa circulação de menções sobre Bolsonaro se originou com uma série de tweets de ambos os filhos do presidente, Eduardo e Flávio, com uma citação atribuída a Winston Churchill, não comprovada ${ }^{9}$. Isso gerou uma cascata de tweets em resposta com a afirmação: "Winston Churchill é a nova Clarice Lispector", nos quais Lispector aparece como paradigma das citações não comprovadas, para legitimar opiniões das mais diversas. A esses tweets se somam outros com falsas citações de Lispector, frases humorísticas, sarcásticas, irônicas, imitando a estrutura e o efeito de uma citação (que é legitimar uma afirmação com o peso de uma autoridade) que viabilizam críticas ao presidente. Um exemplo disso é "'Trump e Bolsonaro vão dizer bobagens inimagináveis a ponto de você querer afundar a cara deles num castelo de areia.' Clarice Lispector (Mas talvez possa ter sido dito por Churchill. Há dúvidas sobre os registros.)", ou "'Doutor, eu não me engano, o Bolsonaro é miliciano' - Clarice Lispector". Esses tweets utilizam a rima, o sarcasmo, o humor, ou mesmo insultos, em frases cujo efeito humorístico advém do contraste entre uma autora prestigiosa, citada normalmente de forma solene, e uma frase que quebra as convenções literárias e normativas. No caso da primeira citação, há um efeito mais intenso, dado pela busca (simulada) pela suposta fonte verídica. Os usuários partem da estrutura da citação para subverter o discurso de prestígio da literatura em forma humorística e mobilizam a autora na direção de uma crítica política com um efeito paródico que subverte o prestígio dos cânones literários.

Nas nuvens de palavras sobre Borges (Figura 4), vemos termos ligados à biblioteca, à leitura, à literatura e ao livro. Também há um grupo de termos relacionados ao mundo onírico e metafísico, como sonho e morte, e outro com sensações e emoções subjetivas, como paranoia, solidão, insônia. Nos tweets sobre Borges em espanhol e português, há um grupo grande de termos ligados à política, como peronista, com 4.145 menções, nacionalista, anar-
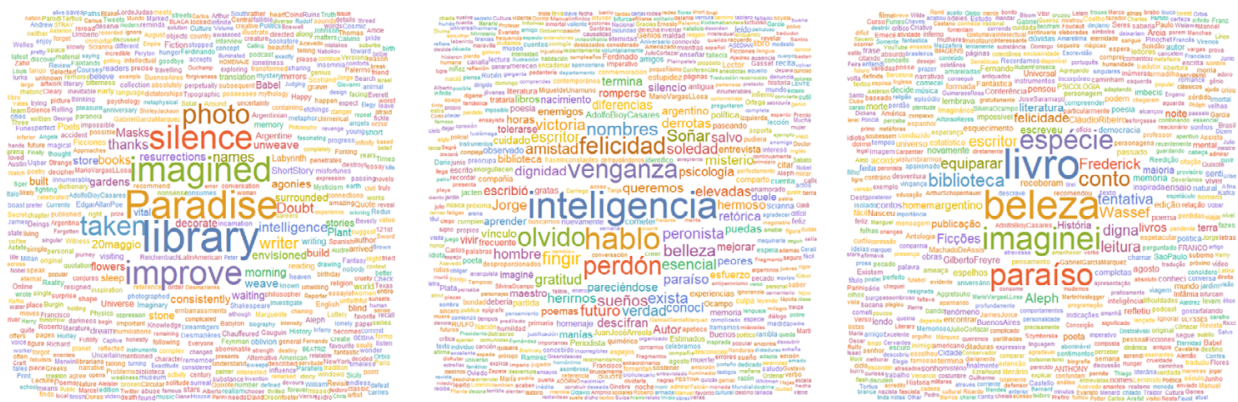

Figura 4 - Nuvens de palavras de tweets sobre Borges em inglês (esquerda), espanhol (centro) e português (direita). 
quismo, comunismo, presidente, democracia, ditadura, opressão, servilismo. Grande parte dos tweets em espanhol que mencionam o peronismo é contrária ao atual governo argentino, que instalou políticas estendidas de isolamento e quarentena ante a COVID-19. Esses tweets consistem em uma série de citações atribuídas e não comprovadas de Jorge Luis Borges nas quais o autor criticaria o peronismo. Esse grupo de usuários é, em sua maioria, conservador, crítico da democracia, alguns se proclamam anticomunistas e outros anarquistas. Em português, há vários tweets de apoio ao presidente brasileiro, e circulam citações como: "A democracia é um erro estatístico, porque na democracia decide a maioria e a maioria é formada de imbecis". 0 caráter polissêmico do Twitter, e do imaginário literário dos autores, possibilita que a mesma frase, dessa vez com hashtags como \#FiqueemCasa e \#BlackLivesMatter, seja utilizada em um sentido ideologicamente oposto, por usuários que criticam a falta de políticas de saúde do governo brasileiro.

Em ambos os corpora de tweets aparecem termos ligados à pandemia e à quarentena, como coronavírus, saúde, COVID e máscaras, com um total de 1.419 em Borges e 922 em Lispector. Muitos desses tweets têm o sentido de divulgação cultural, estimulando as pessoas a ler durante a quarentena, afirmando que seria o momento ideal para a leitura. Os autores são acionados para expressar o medo da morte, da doença, da velhice, a angústia e a ansiedade que invadem a experiência das pessoas em tempos de pandemia. Muitos tweets descrevem a literatura como cura, remédio e companhia nestes tempos, "um placebo sanador em tempos de COVID-19", e incentivam a respeitar as medidas de isolamento e distanciamento social. Circulou, por exemplo, uma imagem da estátua de Lispector na orla da praia no bairro do Leme (Rio de Janeiro) na qual colocaram uma máscara, estimulando a população ao seu uso. Outros tweets expressam a dificuldade de lidar com a solidão e o confinamento e refletem sobre a saúde mental em tempos de quarentena, falam sobre terapias psicológicas (sua escassez e sua necessidade), sobre a própria fragilidade, a necessidade de expressar as emoções, na direção de tirar o estigma da loucura. Paradigmática, a seguinte citação teve ampla circulação no período: "A prova de que estou recuperando a saúde mental, é que estou cada minuto mais permissiva: eu me permito mais liberdade e mais experiências. E aceito 0 acaso. Anseio pelo que ainda não experimentei. Maior espaço psíquico. Estou felizmente mais doida". Lispector é motor de um discurso sobre a saúde mental que quebra os estigmas associados à loucura, à depressão, à doença e ao sofrimento psíquico, servindo como companhia e inspiração para que os leitores explorem seu próprio psiquismo e sua subjetividade, ponto forte para a obra Lispector, motor importante da sua escrita (Josiowicz, 2020). Por seu lado, Borges é bastante acionado para criticar as medidas de distanciamento e isolamento instauradas em vários países, como Venezuela, Colômbia, Equador, Argentina e Brasil. 


\section{MODELAGEM DE TÓPICOS}

a etapa final da pesquisa, extraíram-se os principais tópicos dos tweets por autor
e língua. Com essa finalidade, utilizou-se a técnica de modelagem de tópicos por fatorização ou decomposição de matrizes, chamada Nonnegative Matrix Factorization, e especificamente Probabilistic Latent Semantic Analysis, pela qual é possível extrair os principais tópicos dos tweets. Para tanto, dividimos o texto em documentos para que o algoritmo os classifique em uma série de tópicos, cada um dos quais é representado por um grupo de palavras (Antonov, 2013). Como resultado, geraram-se seis tópicos principais por autor e língua (Figuras 5, 6, 7, 8, 9 e 10).

Em ambos os autores, apareceram os temas da escrita e da leitura e os livros, com certas especificidades: em Borges, termos próprios da literatura do autor, como labirinto, biblioteca, universo, mundos, infinito, espelhos, dão conta do papel da leitura ante as restrições impostas pelo isolamento e distanciamento social.

Outro tópico recorrente em várias línguas e em ambos os autores foi o mundo emocional, na direção da introspecção, a sensação de vazio, a solidão, o silêncio. Também em ambos apareceu o tema onírico e melancólico da noite, a insônia. Em inglês, há outros termos

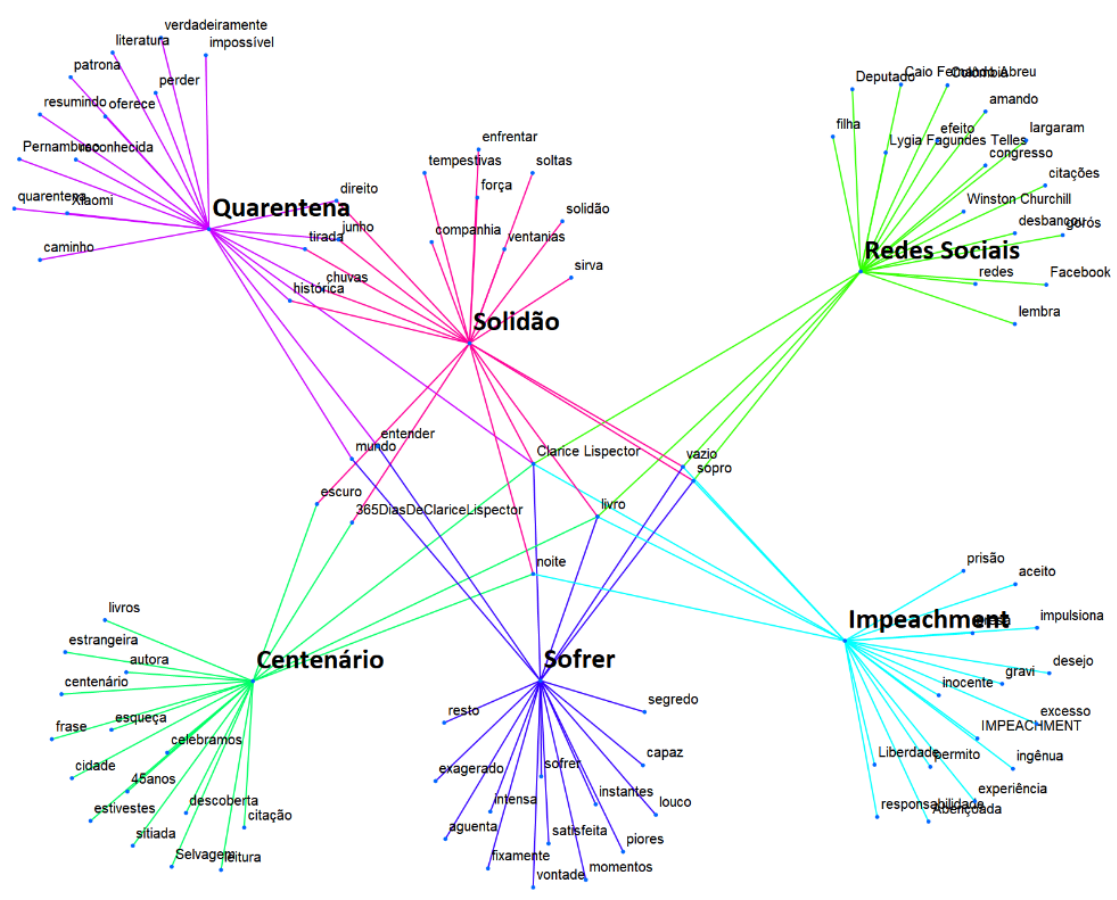

Figura 5 - Tópicos sobre Lispector em português. 


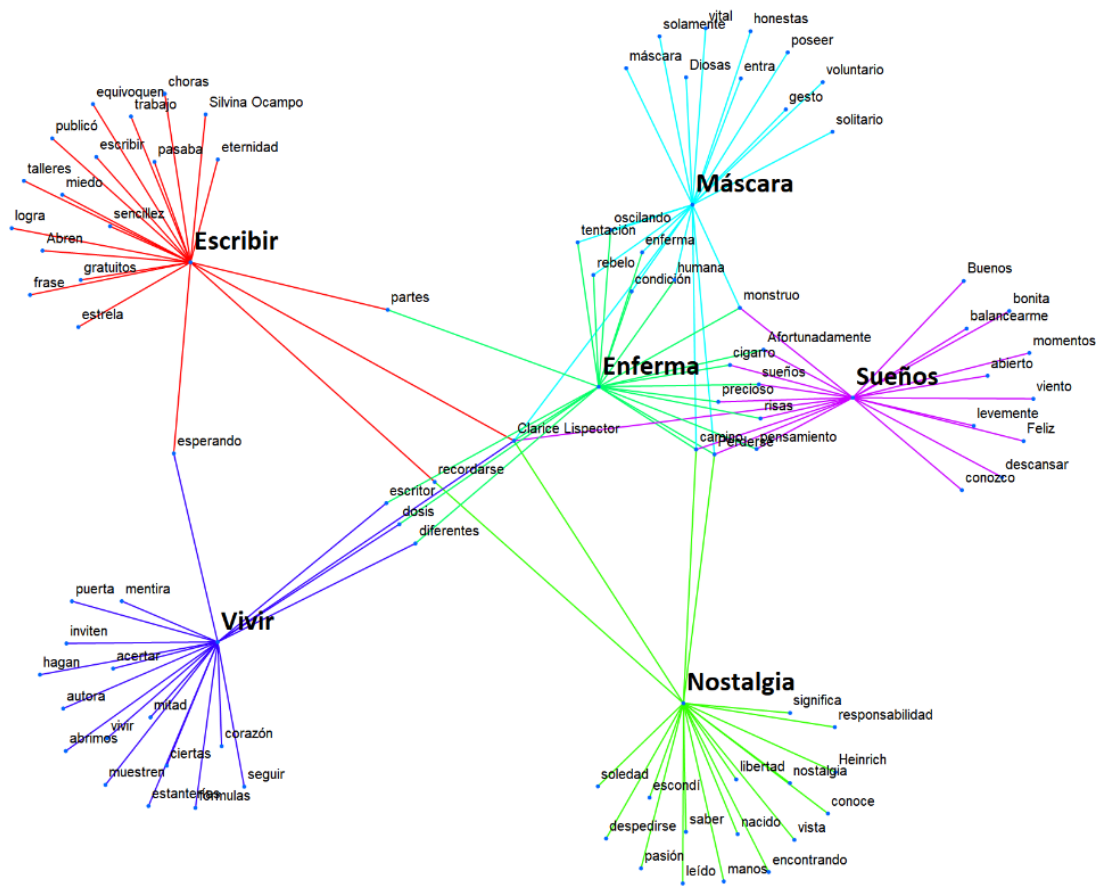

Figura 6 - Tópicos sobre Lispector em espanhol.

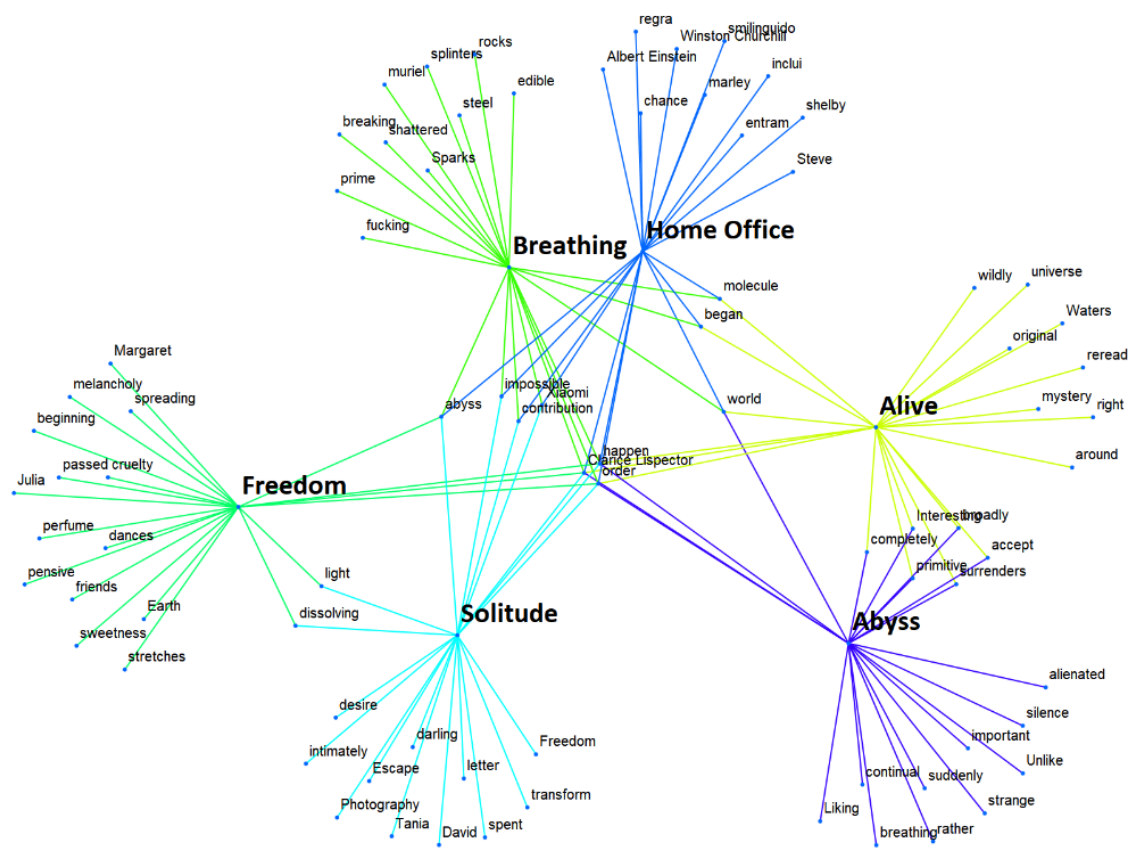

Figura 7 - Tópicos sobre Lispector em inglês. 


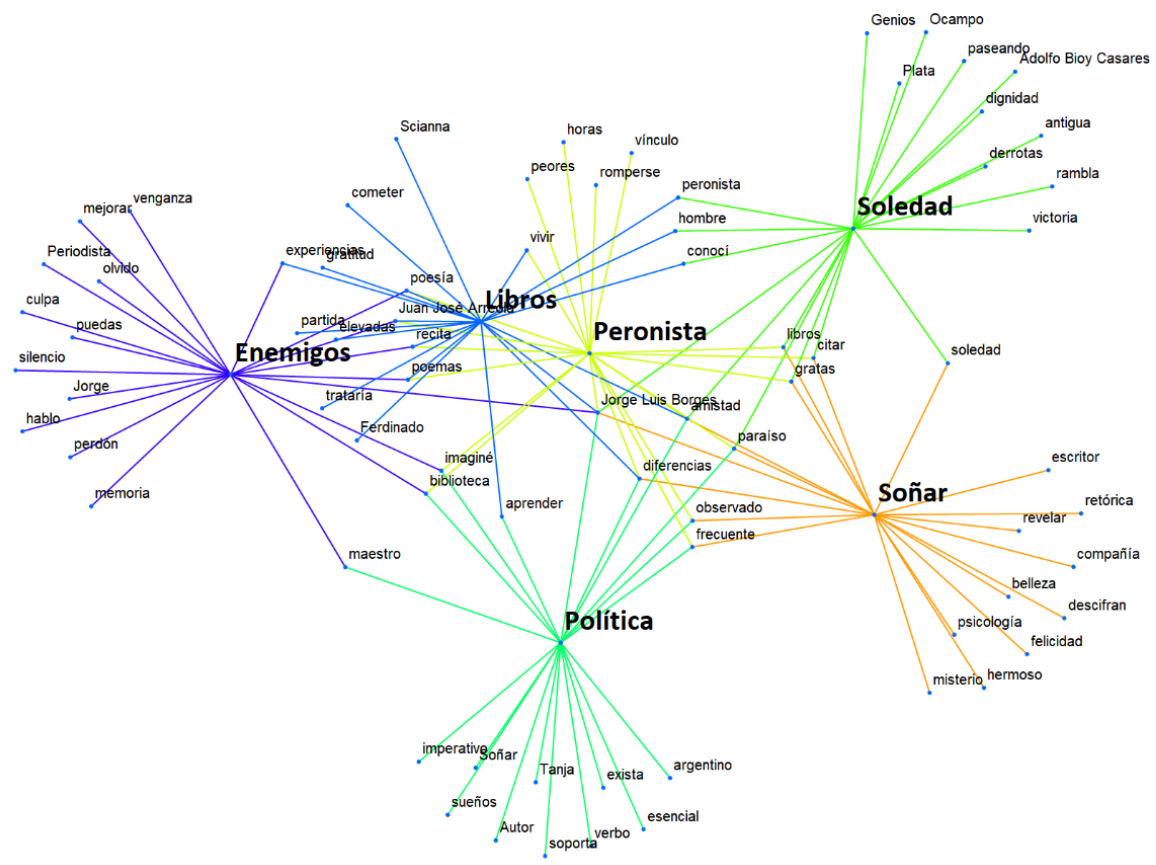

Figura 8 - Tópicos sobre Borges em espanhol.

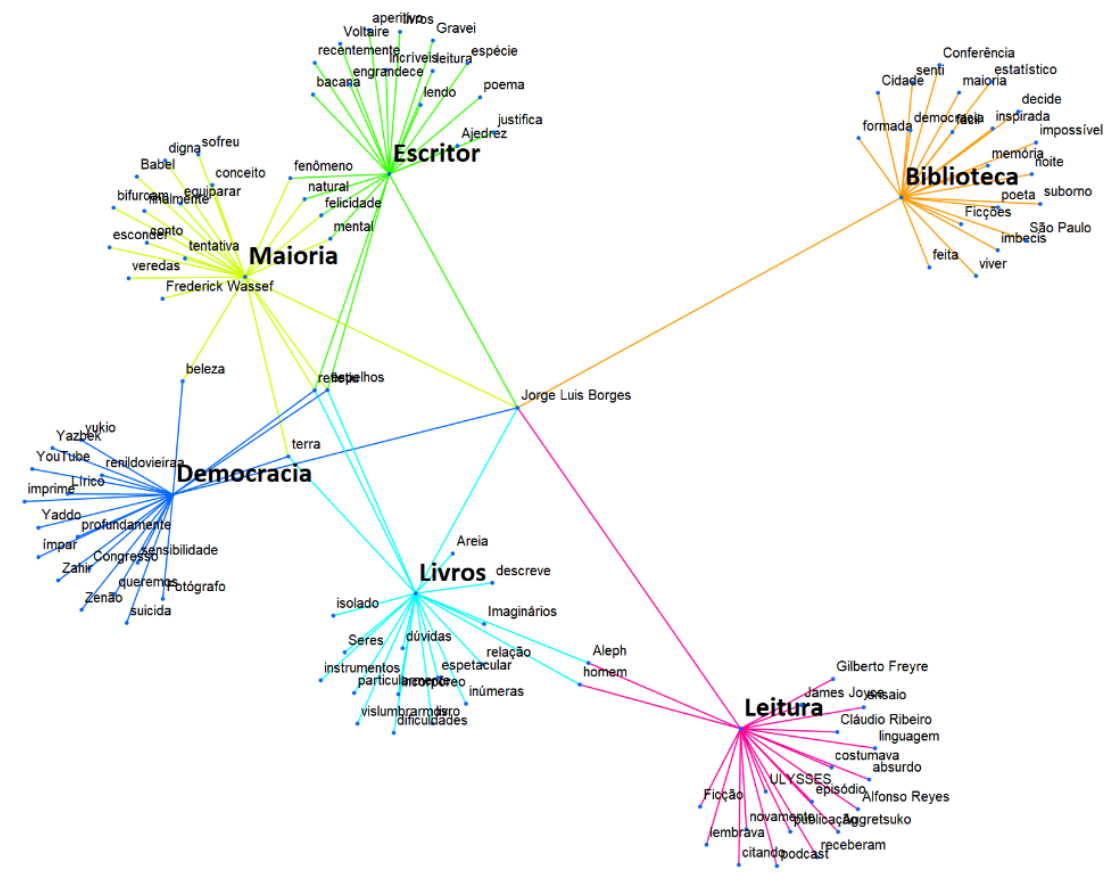

Figura 9 - Tópicos sobre Borges em português. 


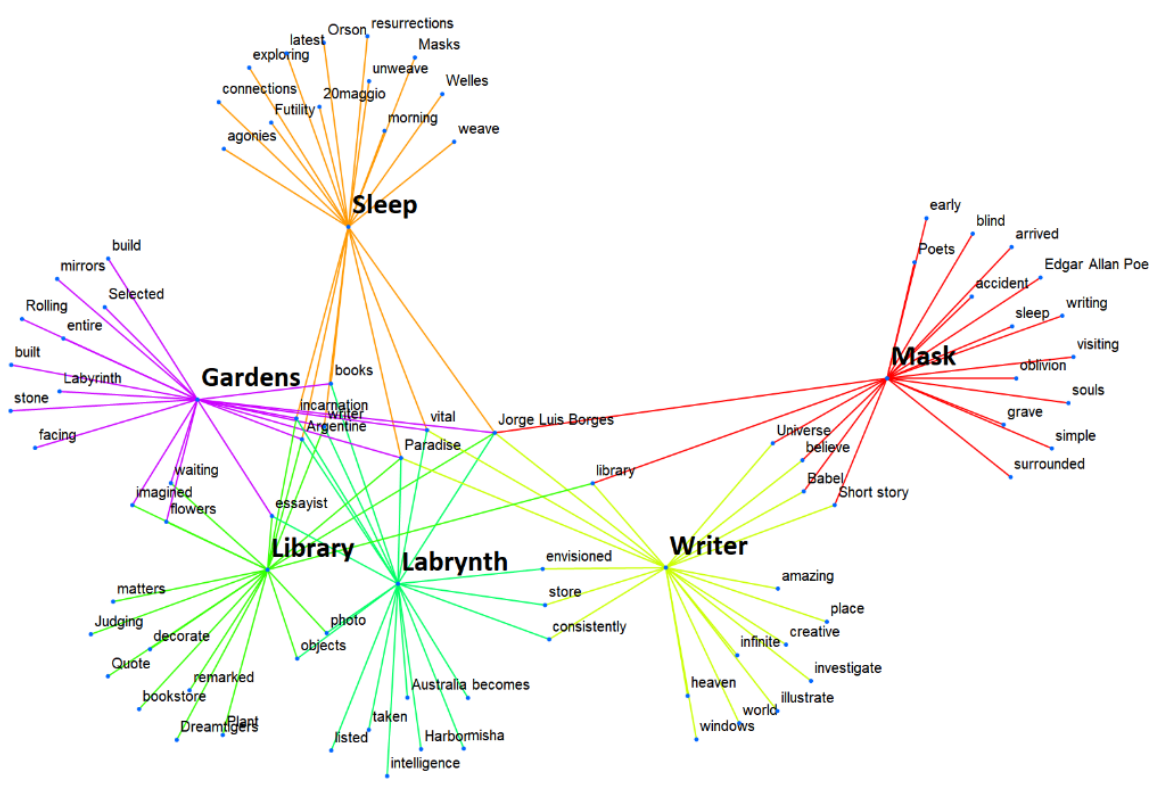

Figura 10 - Tópicos sobre Borges em inglês.

associados à vitalidade e à respiração, centrais na literatura de Lispector e que se tornam fundamentais neste contexto da pandemia pela COVID-19, pelos sintomas respiratórios associados à doença.

Além disso, nos tweets sobre Lispector em várias línguas aparece o tema da liberdade, importante no contexto das restrições decorrentes da pandemia de COVID-19, apontando para variações da citação: "Liberdade é pouco. 0 que desejo ainda não tem nome", Clarice Lispector. A liberdade é valorizada tanto no sentido individual e ante as limitações físicas quanto no sentido coletivo, como luta contra um sistema considerado injusto (a frase é mobilizada de forma polissêmica e em sentidos ideológicos opostos). Inclusive ela se transformou na seguinte frase, simulação de citação de Lispector: "IMPEACHMENT é pouco. O que desejo ainda não tem nome" Clarice Lispector. Vários políticos e celebridades reencaminharam esses tweets, que circularam muito entre os leitores. Esse tweet revela a politização da autora em espanhol e português, dada pela transformação da frase original e incorporação da palavra impeachment. Em contraste, em inglês, esse sentido está ausente.

Entre os leitores de Borges em espanhol e português, há vários tópicos fundamentalmente ligados com a política, com um sentido coletivo da leitura e do uso das redes sociais. 0 peronismo é um deles, acionado entre os usuários hispanos contrários ao atual governo argentino que mobilizam supostas citações atribuídas ao autor no qual ele seria crítico do 
peronismo e narraria sua oposição histórica a esse movimento. Desse modo, os usuários hispanos manifestam sua oposição às políticas de saúde de quarentena obrigatória e isolamento. Termos como inimigos, derrota, vingança e estupidez revelam que esses usuários percebem a realidade de modo altamente contencioso, como luta entre facções opostas e inimigas. Dois tópicos em português, "democracia" e "maioria", revelam uma expressiva presença de tweets críticos da democracia, mobilizados por usuários lusófonos opostos ao governo argentino e a outros governos latino-americanos. No inglês, não aparece nenhum tópico ligado à política, o que não deixa de ser sintomático.

Em todas as línguas e autores aparecem tópicos ligados à quarentena obrigatória, o incentivo ao uso de máscaras, ao respeito das medidas de saúde e políticas de prevenção e distanciamento social (embora em menor medida em inglês). Os tópicos máscara e doença (em espanhol) articulam referências à literatura de Lispector com temáticas próprias da pandemia, como são a proximidade da doença e a morte, dado que as pessoas discutem, refletem, vivem em um quotidiano em que a doença é onipresente. Em inglês, além do tema da respiração, associado aos sintomas da COVID-19, temos o tópico home office, que corresponde a uma série de tweets nos quais os usuários postaram imagens de Lispector na sua biblioteca, fazendo um paralelo entre a necessidade do trabalho em forma remota ao longo da pandemia e o trabalho de escritora de Lispector no âmbito doméstico. Lispector, como escritora paradigmaticamente doméstica — seus textos literários tematizam frequentemente a domesticidade, sua vida com os filhos, como mãe e dona de casa (Josiowicz, 2019) - , tornou-se um paradigma, avant la lettre da necessidade do trabalho remoto na pandemia, como parte do qual o público e o privado, o doméstico e o profissional se confundem na experiência dos leitores. Entre os tweets sobre Borges em inglês, aparece o tema da máscara, que remete ao contexto da pandemia, em que se tornou obrigatória e indispensável (embora não de modo homogêneo entre os públicos).

\section{A LEITURA EM TEMPOS DE PANDEMIA: BORGES E LISPECTOR ANTE A COVID-19}

D esde a segunda metade do século XX e até as primeiras décadas do século XXI, as práticas de leitura de Borges e Lispector deram forma a um universo de temas, um vocabulário compartilhado criado em torno dos seus textos. 0 estatuto de clássicos latino-americanos de Borges e Lispector está intimamente ligado com a continuidade desse universo, nas práticas pelas quais foram lidos e relidos ao longo de décadas, descobertos e redescobertos, sendo moldados pelos diferentes contextos históricos e espaciais e, por sua vez, deixando 
marcas na cultura, nos indivíduos, nas comunidades e nas interpretações (Ludmer, 2010). Lispector e Borges proveram uma gramática, um vocabulário com base no qual as pessoas foram capazes de responder aos dilemas prementes da época. Tornaram-se fontes de reflexão sobre questões contemporâneas, pelo seu poder de interpelação, sua relevância para pensar aspectos de longa duração da existência humana, como instrumentos de comunicação, núcleo de debates e posicionamentos às vezes opostos (Botelho, 2013).

A pandemia de COVID-19 não foi um fenômeno exclusivamente biológico e epidemiológico, mas também social e cultural, que afetou profundamente a relação entre o público e 0 privado, as formas de experimentar e refletir sobre o eu e as emoções, a relação com o próprio corpo e os modos de pensar a cidadania e a representação política (Trindade Lima, 2020). Múltiplas formas de desigualdades sociais, de raça, gênero, etnia e nacionalidade modelaram formas às vezes opostas de experimentar e viver a pandemia entre populações privilegiadas e desprivilegiadas (Hill Collins, 2020).

A circulação de Borges e Lispector no Twitter mostra o impacto que a pandemia de COVID-19 teve nos planos subjetivo e coletivo e qual foi o papel das práticas culturais e literárias nesse contexto. Pelo fato de serem autores presentes na memória cultural e coletiva dos leitores da América Latina e do mundo cosmopolita, como núcleos importantes para refletir sobre questões existenciais, como a saúde mental, a morte e o lugar do humano ante 0 desconhecido, eles tornaram-se importantes no contexto da pandemia de COVID-19. Embora outros autores também tenham circulado, Borges e Lispector foram suficientemente adaptáveis, plásticos e flexíveis para serem relidos e repensados, citados e rescritos por meio de um uso informal, amorfo e difuso das obras. Esse uso desprestigiado pelos cânones acadêmicos tornou-se uma prática útil para processar as transformações do eu e dos afetos, as emoções, a perda e o isolamento e buscar a autocompreensão, o cuidado e a reflexão.

A leitura funcionou como um espaço terapêutico no qual os leitores encontraram refúgio, puderam processar a angústia, assim como experimentar prazer, encantamento e inspiração. Lá conseguiram um canal alternativo ao modo como a televisão, os jornais e as mídias tradicionais modelaram as percepções da pandemia, dado o fluxo de notícias e as estatísticas sanitárias que invadiram o quotidiano das pessoas (Trindade Lima, 2020). As práticas de leitura não só foram impactadas, mas também deram forma à experiência que esses sujeitos tiveram da pandemia. Mais do que uma forma de escape da crise global, a leitura constituiu um modo de processar e estimular mobilizações coletivas, serviu para expressar descontentamento e frustração, para canalizar protestos sociais contra ou a favor das medidas sanitárias, reclamar contra o autoritarismo, a arbitrariedade e a violência. Ante a dificuldade de organizar ações sindicais, mobilizar movimentos sociais ou articular outras 
formas de resistência em um contexto de lockdown (Connel, 2020), Borges e Lispector foram ativados desde extremos ideológicos opostos, por peronistas e antiperonistas, por críticos e apoiadores dos governos, para canalizar ideias diferentes sobre quais deveriam ser as prioridades no contexto da pandemia. Na circulação de Borges e Lispector no Twitter, revela-se quão central tornou-se a economia dos afetos e a interdependência social entre grupos e indivíduos, o modo pelo qual as práticas de leitura encarnaram potentes sentidos coletivos e individuais.

De modos polivalentes, ambíguos e em tensão, os leitores em tempos de pandemia descobriram sentidos nos textos de Lispector e Borges, os leram e releram, construindo e atribuindo novas significações. Dada a força da leitura digital, que só cresceu, junto ao poder das redes sociais, esses autores conseguiram interpelar de modos potentes os públicos. Eles representaram as formas múltiplas de viver a pandemia pela COVID-19, como instrumentos de introspecção, mas também de diálogo e comunicação com a sociedade.

Conflitos de interesse: nada a declarar.

Fonte de financiamento: Não há.

\section{NOTAS}

1 Para um registro histórico e arquivístico da vida intelectual e cultural da pandemia, ver Casa Nova Maia e Casa Nova (2020). Para iniciativas de arquivamento e constituição da memória na COVID-19, ver: Marino et al. (2020). Para uma reflexão sociológica desde o campo do pensamento social no Brasil acerca da vivência da COVID-19 na esfera social, em um sentido tanto teórico quanto empírico, ver o simpósio "Mundo Social e Pandemia", disponível em: https://blogbvps.wordpress.com/category/simposio-mundo-social-e-pandemia/. Acesso em: 14 mar. 2021.

20 Twitter tem atraído o interesse de autores, editoras e poetas por meio da chamada Twitlit (Van Dijck, 2013) e do uso do Book Twitter. O Brasil é o país com mais usuários do Twitter na América Latina e quarto no mundo, com 15,7 milhões de usuários, seguido pelo México e pela Argentina, que está em terceiro lugar na América Latina e $15^{\circ}$ no mundo, com 5,05 milhões de usuários. Disponível em: https://www.statista.com/statistics/242606/number-of-active-twitter-users-in-selected-countries/. Acesso em: 14 mar. 2021.

3 Para outros tipos de abordagens da leitura distante, ver: Santos et al. (2019). 
4 Na chamada estética da recepção, teóricos como Hans Robert Jauss (1994) e Wolfgang Iser (1996) pensaram a leitura como um processo dinâmico e interativo entre o texto e a comunidade de leitores histórica e espacialmente situados.

5 Sobre a intervenção de Borges no mercado literário cosmopolita, ver: Rama (1981), Sarlo (1995), Miceli (2014) e Fishburn (2015). Sobre a participação de Lispector na imprensa jornalística e na indústria cultural, ver: Méndez (2019), Josiowicz (2019).

6 Com base nos testes feitos com escritores como Manuel Puig, Silvina Ocampo e Alfonsina Storni, do lado argentino, e com Nélida Piñón, Lygia Fagundes Telles e Bernardo Carvalho, do lado brasileiro, Borges e Lispector foram considerados os mais produtivos para pensar a leitura em tempos de pandemia no Twitter. Porém outros nomes trariam insights igualmente preciosos e poderão ser explorados em outra oportunidade.

7 A análise restringiu-se àqueles tweets que incluíssem as palavras Clarice Lispector e Jorge Luis Borges, em qualquer ordem.

8 Disponível em: https://techcrunch.com/2018/10/30/twitters-doubling-of-character-count-from-140-to-280-had-little-impact-on-length-of-tweets/. Acesso em: 08 mar. 2021.

9 Disponível em: https://www.bbc.com/portuguese/brasil-52885583. Acesso em: 20 nov. 2020.

\section{REFERÊNCIAS BIBLIOGRÁFICAS}

ALEXANDER, J. Performance and Power. Cambridge: Polity, 2011.

ANTONOV, A. Topic and thesaurus extraction from a document collection. Template Mathematica code using NPR transcripts. 2013. Disponivel em <https://github.com/antononcube/MathematicaForPrediction/ blob/master/Documentation/Topic\%20and\%20thesaurus \%20extraction $\% 20$ from $\% 20$ a $\% 20$ document $\% 20$ collection.pdf>. Acesso em: 20 nov. 2020.

Arêas, V. Clarice Lispector com a ponta dos dedos. São Paulo: Companhia das Letras, 2005.

BERGIS, J.; SUMMERS, E.; MITCHELL, V. Ethical considerations for archiving social media content generated by contemporary social movements: challenges, opportunities and recommendations. 2018. Disponível em: <https://www.docnow.io/docs/docnow-whitepaper-2018.pdf>. Acesso em: 20 jul. 2020.

BOTELHO, A. 0 universo dinâmico dos clássicos da sociologia. In: BOTELHO, A. Essencial Sociologia. São Paulo: Penguin Classics Companhia das Letras, 2013. p. 9-29.

BROCK, A. From the Blackhand Side: Twitter as a cultural Conversation. Journal of Broadcasting \& Electronic Media, v. 56, n. 4, p. 529-549, 2012.

BROCK, A. Análise Crítica Tecnocultural do Discurso. In: SILVA, T. (org.). Comunidades, algoritmos e ativismos digitais: olhares afro-diaspóricos. São Paulo: LiteraRUA, 2020.

BUTLER, J. El capitalismo tiene sus límites. In: V. V. A. A. Sopa de Wuhan. Pensamiento contemporáneo em tiempos de pandemias. Editora ASPO, 2020. p. 59-66. 
CASA NOVA MAIA, A.; CASA NOVA, V. (orgs). Arquivo Pandemia: Diários íntimos, recortes poéticos, históricos, geográficos, políticos, antropológicos, artísticos, psicossociais do isolamento. Belo Horizonte: Editora UFMG, 2020.

CHARTIER, R. Novas tecnologias e a história da cultura escrita. Obra, leitura, memória e apagamento. Leitura: Teoria \& Prática, Campinas, São Paulo, v. 35, n. 71, p. 17-29, 2017. https://doi.org/10.34112/23170972a2017v35n71p17-29

CALLAWAY, E. et al. The push and pull of digital humanities: topic modeling the "what is digital humanities?" genre. Digital Humanities Quarterly. v. 14, n. 1, 2020.

CONNEL, R. Entrevista em Simpósio Internacional Mundo Social e Pandemia. N. 14. BITTENCOURT, A.; HOELZ, M. (orgs.). 2020. Disponível em: <https://blogbvps.wordpress.com/2020/07/02/simposio-14-mundosocial-e-pandemia/ $\geq$. Acesso em: 14 mar. 2021.

FISHBURN, E. Hidden pleasures in Borges's fiction. Pittsburgh University Press, 2015.

HILL COLLINS, P. Entrevista em Simpósio Internacional Mundo Social e Pandemia. N. 14. BITTENCOURT, A.; HOELZ, M. (orgs.). 2020. Disponível em: <https://blogbvps.wordpress.com/2020/07/02/simposio-14-mundosocial-e-pandemia/>. Acesso em: 14 mar. 2021.

ILLOUZ, E. Saving the modern soul. Therapy, emotions and the culture of self-help. Los Angeles: University of California Press, 2008.

ISER, W. O ato da leitura: uma teoria do efeito estético. São Paulo: Editora 34, 1996.

JAUSS, H. R. A história da literatura como provocação à teoria literária. São Paulo: Ática, 1994.

JOSIOWICZ, A. Livros e filhos: políticas de gênero e imaginação sociocultural da infância nas colunas de Clarice Lispector. Journal of Lusophone Studies, v. 4, n. 2, p. 138-157, 2019. https://doi.org/10.21471/jls.v4i2.339

JOSIOWICZ, A. A psicanálise e as transformações na concepção da infância nas crônicas e colunas de Clarice Lispector, 1952-1973. História, Ciência, Aaúde, Manguinhos, v. 27, n.1, p. 53-69, 2020. https://doi. org/10.1590/s0104-59702020000100004

LEE, M.; MARTIN, J. L. Coding, counting and cultural cartography. American Journal of Cultural Sociology, v. 3, p. 1-33, 2015. https://doi.org/10.1057/ajcs.2014.13

LUDMER, J. Qué es un clásico. Blog de Josefina Ludmer, 2010. Disponível em <https://josefinaludmer.

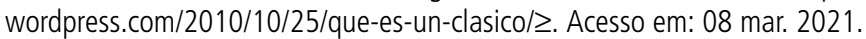

MARINO, I. K. et al. Arquivo, memória e Big Data: uma proposta a partir da COVID-19. Cadernos do Tempo Presente, v. 11, n. 01, p. 90-103, 2020.

MORETTI, F. Literature, measured. Pamphlet 12. Pamphlets of the Stanford Literary Lab., 2016.

MORETTI, F. Patterns and interpretation. Pamphlet 15. Pamphlets of the Stanford Literary Lab., 2017.

MICELI, S.; PONTES, H. (orgs.). Cultura e sociedade: Brasil e Argentina. São Paulo: Edusp, 2014.

Méndez, M. Introduction. Dossier on Clarice Lispector's Journalism. Journal of Lusophone Studies, v. 4, n. 2, 2019.

OLAVE, M. A. T. Reading matters: towards a cultural sociology of reading. American Journal of Cultural Sociology, v. 3, n. 6, p. 417-454, 2018. https://doi.org/10.1057/s41290-017-0034-x 
PRECIADO, P. B. Aprendiendo del virus. In: V. V. A. A. Sopa de Wuhan. Pensamiento contemporáneo em tiempos de pandemias. Editora ASPO, 2020. p. 163-185.

RISAM, R. New Digital Worlds: postcolonial digital humanities in theory, praxis and pedagogy. Illinois: Northwestern University Press, 2018.

SANTOS, D. et al. Preparação para leitura distante em português: diálogos entre PLN e Humanidades Digitais. In: Anais do TILic 2019. Disponível em: <https://www.linguateca.pt/Diana/download/Rochaetal2019.pdf>. Acesso em: 20 nov. 2020.

SARLO, B. Borges, un escritor en las orillas. Buenos Aires: Ariel, 1995.

SARLO, B. El Imperio de los sentimientos. Narraciones de circulación periódica en la Argentina (1917-1927). Buenos Aires: Siglo XXI, 2011.

SARLO, B.; ALTAMIRANO, Carlos. Literatura/Sociedad. Buenos Aires: Edicial, 2001.

Saítta, S. Borges mediático. Variaciones Borges, n. 46, p. 3-22, 2018. http://doi.org/10.2307/26590210

SILVA, T. (org.), Comunidades, algoritmos e ativismos digitais: olhares afro-diaspóricos. São Paulo: LiteraRUA, 2020.

SISKIND, M. Cosmopolitan desires: global modernity and world literature in Latin America. Chicago: Northwestern University Press, 2014.

TRINDADE LIMA, N. Entrevista em Simpósio Internacional Mundo Social e Pandemia. N. 14. BITTENCOURT, A.; HOELZ, M. (orgs.). 2020. Disponível em: <https://blogbvps.wordpress.com/2020/07/02/simposio-14mundo-social-e-pandemia/ $\geq$. Acesso em: 14 mar. 2021.

RAMA, A. El boom en perspectiva. In: RAMA, A. (ed.). Más allá del boom: literatura y mercado. México: Marcha, 1981. p. 51-110.

UNDERWOOD, T. A genealogy of Distant Reading. Digital Humanities Quarterly, v. 11, n. 2, p. 1-12, 2017.

VAN DIJCK, J. The culture of connectivity. A critical history of social media. Oxford: Oxford University Press, 2013.

WILLIAMS, R. Marxism and Literature. Oxford: Oxford University Press, 1977. 